\title{
Impact of preoperative cardiovascular assessment on intraoperative and postoperative cardiovascular complications in cataract surgery
}

\section{Impacto de la valoración cardiovascular preoperatoria sobre las complicaciones cardiovasculares intraoperatorias $y$ posoperatorias en cirugía de catarata}

\author{
Dolores A. González-De la Mora ${ }^{1}$, Ernesto Terán-Martínez², Jazmín I. García Leonardo3*, and \\ José R. Ponce-Martínez ${ }^{1}$
}

\begin{abstract}
${ }^{1}$ Microsurgery of the Anterior Segment department, Hospital General de Mexico Dr. Eduardo Liceaga; ${ }^{2}$ Anesthesiology department, Instituto Nacional de Ciencias Médicas y Nutrición Salvador Zubirán; ${ }^{3}$ Ophthalmology department, Hospital General de México Dr. Eduardo Liceaga; Mexico City, Mexico
\end{abstract}

\begin{abstract}
Background: Cataract is the leading cause of reversible blindness worldwide; however, in Mexico, the rate of surgeries performed is far below ideal due to the lack of access to medical services and the price of the surgical procedure. Although preoperative examinations are always performed, there is no scientific evidence that they reduce the risks of intraoperative and postoperative complications. Objective: To assess whether there is a relationship between intraoperative and postoperative cardiovascular complications and routine preoperative cardiovascular assessments in patients scheduled for cataract surgery in a Mexican population. Method: 327 patients undergoing cataract surgery were included in the ophthalmology service of the Hospital General de México, in which the presence of cardiovascular and/or cerebrovascular complications was evaluated. Results: During the intraoperative period, there were no major vascular events (acute myocardial infarction, cerebrovascular accident, or lethal arrhythmias) regardless of the presence of comorbidity, the type of anesthesia, and the time of surgery for patients with Goldman I and II cardiovascular classification. There were also no major cardiovascular events in the next 7 days. Conclusions: Preoperative cardiovascular assessment has no relationship with intraoperative and postoperative morbidity and mortality of cataract surgery.
\end{abstract}

Key words: Cataract. Preoperative testing. Cardiovascular risk. Acute myocardial infarction. Stroke. Arrhythmia.

\section{Resumen}

Antecedentes: La catarata es la principal causa de ceguera reversible en todo el mundo; no obstante, en México, la tasa de cirugías realizadas se encuentra muy por debajo del ideal debido a la falta de acceso a servicios médicos y al precio del procedimiento quirúrgico. Aunque los exámenes prequirúrgicos se realizan siempre, no hay evidencia científica de que disminuyan los riesgos de complicaciones intraoperatorias y posoperatorias. Objetivo: Evaluar si existe relación entre las

\section{Correspondence:}

*Jazmín I. García Leonardo

Excursionistas del D.F., Manzana 150, Lote 1572

Col. Lázaro Cárdenas

Date of reception: 01-07-2020

Date of acceptance: 16-03-2021

C.P. 54189, Tlalnepantla, Estado de Mexico, Mexico

E-mail: jazmin.irais01@gmail.com

DOI: 10.24875/RMOE.M21000174
Available online: 19-03-2021

Rev Mex Oftalmol (Eng). 2021;95(4):150-153

www.rmo.com.mx

2604-1731/@ 2021 Sociedad Mexicana de Oftalmología. Published by Permanyer. This is an open access article under the CC BY-NC-ND license (http://creativecommons.org/licenses/by-nc-nd/4.0/). 
complicaciones cardiovasculares intraoperatorias y postoperatorias y la valoración cardiovascular preoperatoria sistemática en pacientes programados para cirugía de catarata en población mexicana. Método: Se incluyeron 327 pacientes operados de catarata en el servicio de oftalmología del Hospital General de México, en los que se buscó la presencia de complicaciones cardiovasculares y cerebrovasculares. Resultados: En el intraoperatorio no hubo ningún evento vascular mayor (infarto agudo al miocardio, accidente cerebrovascular o arritmias letales) independientemente de la presencia de comorbilidad, del tipo de anestesia y del tiempo de cirugía para pacientes con clasificación cardiovascular Goldman I y II. Tampoco se presentaron eventos cardiovasculares mayores en los siguientes 7 días. Conclusiones: La valoración cardiovascular preoperatoria tiene nula relación con la morbimortalidad intraoperatoria y posoperatoria de la cirugía de catarata.

Palabras clave: Catarata. Valoración preoperatoria. Riesgo cardiovascular. Infarto agudo de miocardio. Accidente cerebrovascular. Arritmias.

\section{Introduction}

Lens opacity is the main cause of reversible blindness in people over 50 years of age, but despite the high incidence of cataract in Mexico, the rate of surgeries performed is well below the ideal, mainly due to lack of access to medical services and to the price of the surgical procedure, estimating a cost of up to 150 million dollars per year only in the systematic preoperative tests $^{1-4}$.

Although cataract surgery is considered a low-risk surgery, in Mexico all patients must be evaluated to identify the presence of risk factors associated with complications, so a complete blood count and electrocardiogram are systematically requested for patients aged 65 years or more, regardless of their health status; other tests, such as chest x-ray, blood clotting tests, and urinalysis, are also frequently requested ${ }^{5}$.

Until now, there are no studies showing that the preoperative evaluation reduces the risk of intraoperative and postoperative systemic complications or increases the safety of surgery. In some developed countries, low-risk patients are scheduled for surgery by omitting "routine examinations", thereby significantly reducing the costs of cataract surgery, and increasing the efficiency of the system ${ }^{6,7}$.

Due to the uncertainty about the effectiveness of these tests, the present study aims to evaluate whether medical tests and systematic cardiovascular evaluation before cataract surgery reduce the rate of intraoperative and postoperative cardiovascular complications in the Mexican population.

\section{Methods}

An analytical, descriptive, prospective, and non-experimental observational study was carried out in the period between March 2017 and February 2018 at the Hospital General de Mexico. We included patients of any age and sex diagnosed with cataract, with laboratory tests and a cardiovascular evaluation according to the Goldman scale, who underwent surgical treatment. We excluded patients without a cardiovascular evaluation, with congenital cataracts, traumatic cataracts, and those in whom cataract surgery was performed combined with some other procedure.

The patients signed an informed consent form in accordance with the General Health Law and the Declaration of Helsinki. This study was evaluated and approved by the ethics committee of the Hospital General de México with registration code DIR/17/102/3/012.

Through direct questioning and review of records, the following demographic and clinical data were obtained: age, sex, comorbidities, and cardiovascular risk on the Goldman scale, surgical technique, academic degree of the surgeon and type of anesthesia used.

The presence of cardiovascular complications, such as ischemia, myocardial infarction, and cerebrovascular accident, was evaluated, for which the anesthesiology service carried out intraoperative surveillance recording the systolic (SBP), diastolic (DBP) and mean (MBP) blood pressure in 10-minute intervals, and heart rhythm by continuous electrocardiographic recording. Neurological status was assessed before and after the intervention using the National Institute of Health Stroke Scale until discharge from the ophthalmology department. These tests were repeated one week after surgery.

The data were analyzed using the Student's t-test for independent samples in the quantitative variables, with a $95 \%$ confidence interval. Categorical variables were analyzed using the statistical package STATA 14 for Windows. All analyses were carried out considering a value of $p<0.05$ to be significant.

\section{Results}

We studied 327 patients, 58\% women and $42 \%$ men, with a mean age of 66 years (range: 26 to 94 ). 
Phacoemulsification was performed in $82 \%$ of the patients, while the remaining $18 \%$ underwent extracapsular cataract extraction.

Sixty-eight percent of the patients were operated on by residents in training in anterior segment microsurgery and the remaining $32 \%$ by the ophthalmologist assigned to the ophthalmology department.

Within the clinical profile of the patients, $73.7 \%$ had an associated systemic disease; the most frequent were arterial hypertension in $55.6 \%$, followed by type 2 diabetes mellitus in $45.8 \%$. There was altered tolerance to carbohydrates in $2.14 \%$ of the patients (Table 1).

In the cardiovascular evaluation, $58 \%$ were classified as category II and $42 \%$ as category I in the Goldman scale.

The anesthesia modality used was retrobulbar block plus topical anesthesia in $62 \%$, intracameral anesthesia in $21 \%$, retrobulbar block in $16 \%$, intravenous sedation in $0.2 \%$, and general anesthesia in $0.1 \%$ (Fig. 1).

For SBP, a difference was obtained between the initial and final values of the surgery of $0.36 \mathrm{mmHg}$, with a Student's t of 0.7; for DBP, Student's t-value was 0.9, with a difference of $0.06 \mathrm{mmHg}$; and for MBP, Student's $t$ value was 1.0 with a difference of $-0.01 \mathrm{mmHg}$.

During the intraoperative period, there were no major cardiovascular events (acute myocardial infarction, cerebrovascular accident, or fatal arrhythmias). There were no major cardiovascular events in the 7 postoperative days either.

\section{Discussion}

The American Heart Association and the European Society of Cardiology guidelines for cardiovascular evaluation and management in non-cardiac surgery, establish that cataract surgery has a risk of less than $1 \%$ of major cardiovascular complications. This study shows that the incidence of cardiovascular complications is even closer to zero.

Sex, age, or comorbidities do not appear to be risk factors for cardiovascular complications.

There was no difference between the type of anesthesia used and the presence of cardiovascular complications, so the anesthetic modality does not appear to confer any protective factor or add a risk factor for cardiovascular complications.

Despite the fact that surgeons in training spend a longer surgical time, this was not a risk for cardiovascular complications.

It is important to mention that the Goldman index is the only cardiovascular scale used in the preoperative
Table 1. Comorbidity frequency

\begin{tabular}{|l|c|}
\hline Comorbidity & Percentage (n) \\
\hline Mild arterial hypertension & $55.6 \%(182)$ \\
\hline Type 2 diabetes mellitus & $45.8(150)$ \\
\hline Impaired carbohydrate tolerance & $2.14 \%(7)$ \\
\hline Ischemic heart disease + stent & $0.3 \%(1)$ \\
\hline History of cardiac arrhythmia & $0.6 \%(2)$ \\
\hline Stroke & $0.6 \%(2)$ \\
\hline None & $26.2 \%(86)$ \\
\hline
\end{tabular}

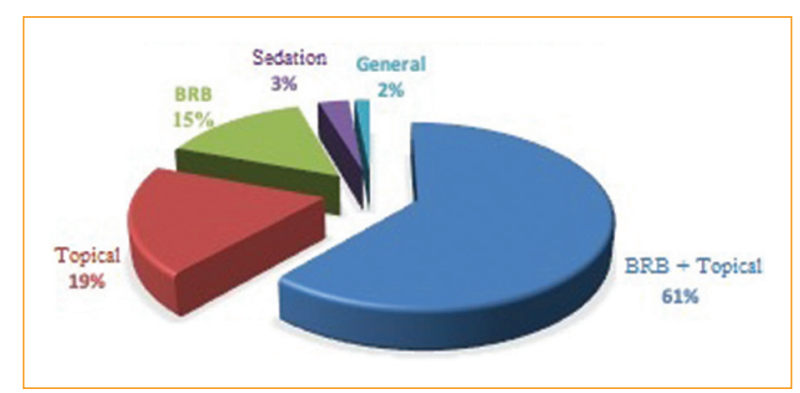

Figure 1. Type of anesthesia. BRB: retrobulbar block.

assessment at the Hospital General de Mexico, and one of the most frequently used for the Mexican population in general, and that cataract surgery is mainly performed on an outpatient basis at the Hospital General de Mexico, the main reason why the patients included in this study presented a Goldman I and II assessment, since patients with Goldman IV usually have a significant deterioration in their general condition that prevents them from attending an ocular examination under slit-lamp. However, several studies have shown that this scale is not very specific for predicting cardiovascular complications, which is why in recent years others have been described, such as P-POSSUM, GUPTA and NSQIP, which, according to the studies carried out, show clinical and statistic results that could be applied to the Mexican population.

Our study is the first to carry out a review to evaluate the usefulness of systematic medical tests before cataract surgery in the rate of perioperative complications in a Mexican population with comorbidities.

We suggest that patients scheduled for cataract surgery be assessed and stratified in the outpatient ophthalmology clinic in accordance with current international scales for cardiovascular risk to be able to identify 
patients who really deserve an extended assessment by internal medicine, cardiology, or anesthesiology.

\section{Conclusions}

We present the first study focused on evaluating whether systematic preoperative tests are useful to reduce the rate of perioperative complications in cataract surgery in the Mexican population, concluding that, regardless of the presence of comorbidities, the type of anesthesia and the duration of surgery, the cardiovascular risk associated with cataract surgery remains low $(0 \%)$ for patients with Goldman I and II cardiovascular classification, so ophthalmologists should have the capacity to evaluate and stratify in the outpatient ophthalmology consultation which patients deserve an extended assessment by internal medicine, cardiology or anesthesiology, which could be carried out effectively using the new preoperative assessment scales with the aim of reducing the high costs of a systematic preoperative assessment, avoiding delays in scheduling surgery and decrease the rate of reversible blindness caused by cataracts.

\section{Funding}

This article was prepared with resources from the Ophthalmology Service at the Hospital General de México "Dr. Eduardo Liceaga".

\section{Conflicts of interest}

The authors of this article declare that they have no conflict of interest, as well as any economic, personal, or political relationship.

\section{Ethical disclosures}

Protection of human and animal subjects. The authors declare that no experiments were performed on humans or animals for this study.

Confidentiality of data. The authors declare that they have followed the protocols of their work center on the publication of patient data.

Right to privacy and informed consent. The authors declare that no patient data appear in this article.

\section{References}

1. Agarwal A, Kumar DA. Cost-effectiveness of cataract surgery. Curr Opin Ophthalmol. 2011;22:15-8.

2. Lee CM, Afshari NA. The global state of cataract blindness. Curr Opin Ophthalmol. 2017;28:98-103.

3. Lansingh VC, Resnikoff S, Tingley-Kelley K, Nano ME, Martens M, Silva JC, et al. Cataract surgery rates in Latin America: a four-year longitudinal study of 19 countries. Ophthalmic Epidemiol. 2010;17:75-81.

4. Batlle JF, Lansingh VC, Silva JC, Eckert KA, Resnikoff S. The cataract situation in Latin America: barriers to cataract surgery. J Ophthalmol. 2014;158:242-50.

5. Committee on Standards and Practice Parameters; Apfelbaum JL, Connis RT, Nickinovich DG, American Society of Anesthesiologists Task Force on Preanesthesia Evaluation; et al. Practice advisory for preanesthesia evaluation: a report by the American Society of Anesthesiologists Task Force on Preanesthesia Evaluation. Anesthesiology. 2002:96:485-96.

6. Keay L, Lindsley K, Tielsch J, Katz J, Schein O. Routine preoperative medical testing for cataract surgery. Cochrane Database Syst Rev. 2012;(3):3-6.

7. Schein OD, Katz J, Bass EB, Tielsch JM, Lubomski LH, Feldman MA, et al. The value of routine preoperative medical testing before cataract surgery. Study of Medical Testing for Cataract Surgery. N Engl J Med. 2000;342:168-75. 